\title{
El Capítulo Nicaragua y su articulación con el Comité Consultivo del Sistema de Integración Centroamericana (CCSICA $)^{1}$
}

\author{
Hloreley Osorio Mercado*, Mario Sánchez González y Marissa Oliva- \\ res Morales ${ }^{* * *}$
}

Recibido: marzo de 2013 / Aceptado: octubre de 2013

Desde 2005 el Comité Consultivo del Sistema de Integración Centroamericana (CCSICA) dispone de capítulos nacionales en cada uno de los países centroamericanos (a excepción de El Salvador). La investigación muestra la trayectoria que ha tenido el Capítulo Nicaragua y su articulación con el CCSICA, cuyos mecanismos de comunicación, retroalimentación y seguimiento al capítulo nacional han sido débiles. El estudio reveló que el Capítulo Nicaragua está en proceso de constituirse en un espacio para reflexión, análisis y promoción de la integración centroamericana. Entre sus retos están la ampliación y el fortalecimiento de su liderazgo, y el establecimiento y regularización de los mecanismos de funcionamiento y comunicación entre sus miembros. Su labor ha sido de posicionamiento político, pero hace falta desarrollar

\footnotetext{
1 Este artículo es uno de los resultados de cuatro investigaciones realizadas en el marco del "Proyecto de investigación interuniversitaria regional sobre la situación y perspectiva del proceso de integración centroamericana como marco para el desarrollo de la región", financiado por la Agencia Española de Cooperación Internacional para el Desarrollo (AECI). Las entidades participantes fueron la Universidad Centroamericana José Simeón Cañas de El Salvador, la Universidad Centroamericana de Managua y la Facultad de Ciencias Empresariales adscrita a la Universidad de Córdoba, España (ETEA). Para una revisión más amplia de los hallazgos, ver: Sánchez González, M., Osorio Mercado, H. Ë Olivares Morales, M. (2013). El Capitulo Nicaragua y su articulación con el Comité Consultivo del SICA. En O. Miranda Ë F. Santos Carrillo (eds.). Situación y perspectiva del Proceso de Integración Centroamericana como marco para el desarrollo de la región: Una aproximación universitaria. San Salvador: Talleres Gráficos UCA.

* Centro de Análisis Sociocultural - Universidad Centroamericana (CASC-UCA). Correo electrónico: hloreley1@yahoo.com

**Centro de Análisis Sociocultural- Universidad Centroamericana (CASC-UCA), Correo electrónico: m.sanchez@ns.uca.edu.ni

*** Facultad de Humanidades y Comunicación Social, Universidad Centroamericana (UCA). Correo electrónico: marissao@ns.uca.edu.ni
} 
capacidades técnicas para formulación de propuestas, incidencia y auditoría, un mayor involucramiento de la ciudadanía local en los procesos de integración regional y la dinamización de su comunicación con el CCSICA.

Palabras clave: espacios consultivos / Capítulo Nicaragua / Comité Consultivo del Sistema de Integración Centroamericana

\section{Introducción}

En el proceso de integración centroamericana se ha reconocido que el desarrollo y la democracia en la región necesitan de la participación protagónica de la sociedad civil. Este es un concepto ambiguo por no tenerse claro quién es el interlocutor natural de la sociedad civil regional. En palabras de Castells (2000, citado por Santos, 2010, p. 126) "el concepto de sociedad civil alude a un mecanismo de representación y defensa de los ciudadanos que desborda las instituciones del Estado propiamente dicho, pero siempre teniendo dicho Estado como interlocutor y punto de referencia”. Como señala Santos (2010), en el caso de la integración regional es el Estado quien ha venido confeccionando la agenda del proceso integracionista.

En el ámbito regional funcionan cuatro espacios:

- El Comité Consultivo del Sistema de Integración Centroamericana (CCSICA);

- El Comité Consultivo de la Secretaría de Integración Económica Centroamericana (CCIE);

- $\quad$ El Comité Consultivo de la Integración Social, constituido como mesa sectorial del CCSICA en virtud del convenio suscrito por éste con la Secretaría de Integración Social Centroamericana;

- $\quad$ Y un mecanismo de participación indirecta en el Tratado Marco de Seguridad Democrática (2001) a través de la Secretaria General del SICA (SGSICA) y del CCSICA.

Desde 2005 el CCSICA cuenta con capítulos nacionales en cada uno de los países centroamericanos (a excepción de El Salvador). Dichos espacios tienen logros y dificultades. Se han congregado para emitir pronunciamientos y propuestas sobre diversos temas regionales, uno de éstos fue el Acuerdo de Asociación entre la Unión Europea y Centroamérica con la UE (AdA). No obstante, pese a que se trata de espacios institucionalizados, el seguimiento, la operatividad y la incidencia han sido muy débiles. De acuerdo a Santos Carrillo (2010), la debilidad de los capítulos nacionales procede de las limitantes de las organizaciones de la sociedad civil nacionales y de la integración centroamericana, que no ha sido capaz de articular procesos de difusión sobre su naturaleza.

Se trata de espacios que actúan de forma irregular. La falta de recursos del CCSICA es el principal motivo, puesto que se nutren de recursos de las organizaciones que representan o de la gestión de fondos que logran como capítulo nacional. Sus propuestas, en general, son muy irregulares y requieren de acompañamiento técnico para situar a los participantes en la realidad de la integración centroamericana. 
Costa Rica y Nicaragua son una excepción, ya que se configuran como los capítulos más activos a la hora del análisis de la situación y de las propuestas elaboradas, tal como se muestra en las memorias de los talleres de constitución de los capítulos. Además, el directorio de los capítulos nacionales está compuesto mayoritariamente por representantes de organizaciones nacionales miembros del CCSICA, lo que provoca la superposición de los intereses de las organizaciones de sociedad civil regional sobre las del Capítulo Nicaragua.

Ha existido una escasa articulación entre los capítulos nacionales y el CCSICA, careciendo este último de organización y de seguimiento a la Agenda Regional del SICA. Esto no desdice que el CCSICA ha mostrado interés en iniciar la identificación de organizaciones y líderes del ámbito nacional para establecer mecanismos de comunicación y flujos de información que permitan formular propuestas de incidencia.

Realizamos un análisis de uno de los capítulos más dinámicos- el Capítulo Nicaragua-, tratando de perfilar su funcionamiento interno, articulación con el CCSICA y el resto de los capítulos nacionales y las lecciones aprendidas.

El estudio concibe a la sociedad civil como la expresión de las asociaciones $\mathrm{u}$ organizaciones y los movimientos sociales que, actuando a distintos niveles geográficos (local, nacional y regional), son ajenos al Estado, representan intereses diversos y trascienden el universo privado en el que surgen. Ahora bien, el CCSICA no tiene un interlocutor claro, mientras que en el caso de los Capítulos Nacionales, su interlocutor parece ser el CCSICA.

El método de investigación fue cualitativo, de alcance descriptivo. Se realizó análisis documental y se aplicó nueve entrevistas semi-estructuradas a representantes de organizaciones del Capítulo Nicaragua divididas de la siguiente manera: el total de miembros del directorio del capítulo nacional (tres miembros de organizaciones nacionales que tienen representación regional en el CCSICA y tres miembros de organizaciones nacionales o regionales residentes en el país) y tres miembros de la asamblea plenaria del capítulo nacional. También se hicieron dos entrevistas exploratorias dirigidas a informantes clave (a un experto en el tema y al presidente del CCSICA). Aunque se pretendió triangular los datos del Capítulo Nicaragua con información derivada de los miembros del CCSICA, esto no fue posible pues no obtuvimos respuesta de parte del espacio consultivo global.

Se espera que el estudio contribuya al debate, la reflexión y la generación de conocimientos sobre la integración regional en las universidades de la Compañía de Jesús del área centroamericana. Los resultados serán insumos para el proyecto curricular interuniversitario en el mediano y largo plazo.

\section{La sociedad civil en Nicaragua: historia, organizaciones y marco jurídico}

\subsection{Etapas de desarrollo de la sociedad civil en Nicaragua}

Las etapas de desarrollo de la sociedad civil han sido descritas por Serra (2010). En la época del Régimen Somocista (1936-1979) el gobierno promovió la formación de organizaciones comunales, sindicales, juveniles y gremiales afines al régimen, cuyos 
líderes eran cooptados mediante mecanismos clientelistas (Walter, 2004, citado por Serra, 2010).

En los 60 y 70 se conformaron sindicatos de trabajadores - la mayoría promovidos por el Partido Socialista - que se aglutinaron en confederaciones sindicales, asociaciones empresariales articuladas en el Consejo Superior de la Empresa Privada (COSEP), organizaciones de desarrollo y cooperativas. Cabe destacar que las cooperativas de ahorro, crédito y servicios múltiples fueron impulsadas por instituciones religiosas, el sector empresarial y la Agencia Internacional de Desarrollo de los Estados Unidos (USAID), como parte del programa Alianza para el Progreso. Mientras, el pequeño grupo de organizaciones de desarrollo estaba vinculado mayoritariamente al ámbito religioso. Sobresalen las Comunidades Eclesiales de Base (CEB's), influidas por la Teología de la Liberación, quienes logran constituirse como un espacio de reflexión crítica y de organización ciudadana frente al sistema político represivo.

A finales de los 70 surgen organizaciones civiles vinculadas al Frente Sandinista de Liberación Nacional (FSLN): la Asociación de Educadores (ANDEN), la Asociación de Trabajadores del Campo (ATC), los Comités de Defensa Sandinista (CDS), la Asociación de Mujeres por la Problemática Nacional (AMPRONAC), el Frente Estudiantil Revolucionario (FER), el Movimiento Estudiantil de Secundaria (MES) y la Asociación de Estudiantes de Secundaria (AES).

En la Costa Caribe se han mantenido organizaciones y autoridades comunitarias propias, tales como los Consejos de Ancianos, el juez, el síndico, y espacios de participación ciudadana como las Asambleas Comunales. También las iglesias más importantes (morava y católica) promovieron organizaciones sociales que contribuyeron al desarrollo local.

Durante la época revolucionaria (1979-1989) predominaron las organizaciones civiles sandinistas y aliadas al partido de gobierno, las cuales disponían de agendas determinadas mayoritariamente por las decisiones e intereses políticos del FSLN. Las organizaciones de sociedad civil (OSC) tenían una triple finalidad: participar en la resolución de los problemas de los sectores sociales, movilizar al pueblo en el cumplimiento de planes del gobierno y en su defensa militar, y desarrollar cuadros para fortalecer el partido (Ruchwarger, 1985, citado por Serra, 2010). En estas organizaciones el poder se concentraba en los dirigentes superiores nombrados por el FSLN, aunque éstos realizaban consultas anuales con sus bases, que eran gestionadas ante instancias estatales u organizaciones civiles de cooperación externa.

La relación entre las OSC y el Estado era ambigua: por un lado, las organizaciones sandinistas defendían al gobierno revolucionario frente a la oposición, y por otra parte, criticaban su burocracia, reclamaban participación en las políticas públicas, y demandaban recursos materiales para ejecutar sus propios planes. Se crearon instancias de gobernanza donde las organizaciones civiles sandinistas eran consultadas sobre las políticas públicas.

El gobierno otorgó personería jurídica a 138 asociaciones civiles: 32 de carácter religioso; 29 organizaciones profesionales, 28 sindicatos; 6 organizaciones de filiación sandinista; 2 organizaciones de productores y 41 de diversas áreas. Además, se habían instalado en el país unas 120 OSC de otros países que colaboraron con las OSC nicaragüenses y con el Estado en distintos proyectos socioeconómicos 
para hacer frente al bloqueo comercial y la agresión estadounidense. A través de hermanamientos surgen espacios de cooperación descentralizada entre ONG, movimiento campesino, obreros, mujeres y gobiernos locales.

Las pocas organizaciones opuestas al proyecto sandinista fueron algunos sindicatos vinculados a otros partidos políticos, gremios empresariales aglutinados en el COSEP, organizaciones de derechos humanos y organizaciones indígenas del Caribe.

Pese a las limitaciones señaladas las OSC aprendieron a organizarse, a realizar incidencia pública y a demandar derechos.

La etapa de expansión (1990-2006) coincide con gobiernos neoliberales que producen cambios profundos en el Estado y la sociedad civil. Tal como afirma Ortega (2008, p.11), "a partir de 1990, la sociedad civil nicaragüense se vio obligada a organizarse desde abajo, y con autonomía de los partidos políticos y del gobierno". Es un período que se caracteriza por la reducción de las OSC sandinistas, el surgimiento de nuevas organizaciones de origen sandinista pero autónomas del FSLN (entra las que se destacan las organizaciones de mujeres que reivindican sus derechos) y la oleada de asociaciones sin fines de lucro o fundaciones (en el año 1996, había 1,369 asociaciones inscritas en el Ministerio de Gobernación) que trabajaban en la promoción de los derechos de grupos excluidos, agro-ecología y medio ambiente, salud y rehabilitación, derechos humanos, crédito, cultura y ciudadanía, con apoyo de la cooperación internacional. Estas asociaciones de desarrollo, aunque no pretendían sustituir al Estado, respondían a problemas sociales que el Estado no resolvía debido a las políticas neoliberales impuestas, la oferta de fondos y asistencia técnica de la cooperación internacional y la flexibilidad legal para formar una organización sin fines de lucro.

Los gremios empresariales articulados en el COSEP fueron los interlocutores privilegiados del gobierno en la definición de políticas públicas, así como los beneficiados por la privatización de empresas estatales. También se produjo el proceso de articulación de las OSC en redes o federaciones temáticas o sectoriales que intercambian experiencias, realizaban acciones conjuntas e incidían en políticas públicas. Uno de los resultados más visibles de las redes ha sido la incidencia en políticas públicas, como la ley que penaliza la violencia contra las mujeres (Ley 230. 1990), la Ley del Medio Ambiente (217-1996), la Ley de Promoción, Protección y Defensa de los Derechos Humanos ante el SIDA (Ley 238-1996) y el Código de la Niñez y Adolescencia (Ley 287-1998), entre otras.

La labor realizada por la Coordinadora Civil de Emergencia y Reconstrucción (CCER) durante el Huracán Mitch obtuvo el reconocimiento de la población y la comunidad internacional. En 1999 se conformó el Consejo Nacional de Planificación Económica y Social (CONPES) como instancia de concertación Estado-Sociedad. También surgió el Consejo Nacional de Desarrollo Sostenible (CONADES), con participación de OSC y entes estatales, como un foro de análisis y propuestas de políticas de desarrollo sostenible conforme a los lineamientos de la Agenda 21 aprobada en la Cumbre de Río de 1992.

Durante el gobierno de Arnoldo Alemán (1997-2001) hubo control de las OSC no afines al Partido Liberal Constitucionalista (PLC) a través del marco legal que regula las $\mathrm{OSC}$, aunque también se trató de regular los fondos de cooperación 
a los que accedían. Por el contrario, durante la administración del Gobierno de Enrique Bolaños (2002-2006) se abrieron espacios de consulta con la sociedad civil y espacios de concertación de políticas públicas amparados en la Ley de Participación Ciudadana (475-2003) como una manera de contrarrestar el poder que tenían los partidos políticos de oposición (PLC y FSLN) en la Asamblea Nacional. También se aprobó la Ley de Acceso a la Información Pública (621-2007), así como leyes sectoriales: Ley de Participación Educativa (413-2002) y la Ley General de Salud (423-2003).

Las organizaciones étnicas del Caribe lograron en esa época la aprobación del Reglamento del Estatuto de Autonomía, la Ley de Titulación de Territorios Indígenas, el reconocimiento de autoridades y de sus propuestas en leyes nacionales de educación, salud, pesca, forestal, agua y turismo, y la elaboración de planes de desarrollo de las Regiones Autónomas del Norte y del Sur, y la Agenda Costeña de Desarrollo.

Por otra parte, la participación de la sociedad civil en el proceso de integración centroamericana es reciente. Desde la creación del CCSICA, en 1995, han participado en la agenda de integración tres organizaciones nacionales asociadas a redes regionales miembros del espacio consultivo en cuestión. Éstas son: Coordinadora Centroamericana de Trabajadores (COCENTRA), Consejo Indígena Centroamericano y Foro de Mujeres para la Integración Centroamericana (FMICA). Desde 2005 existen cuarenta organizaciones civiles nicaragüenses (en su mayoría de carácter nacional) que han participado en el Capítulo Nicaragua. Se trata de OSC que han hecho incidencia y propuestas sobre medio ambiente, derechos laborales, institucionalidad del SICA y, más recientemente, frente al Acuerdo de Asociación de Centroamérica y la Unión Europea (AdA) y Acuerdo de Esquipulas III o Esquipulas de los Pueblos.

El período de polarización (2007-2011) comienza con el triunfo electoral del FSLN en las elecciones presidenciales de 2006. Dicho gobierno impulsó la creación de los Consejos o Gabinetes de Poder Ciudadano (CPC o GPC) que se forman a nivel local y municipal organizados por militantes del FSLN (Decreto 03-2007), creando tensiones con el sistema legal pues se duplican las instancias de participación y se ignoran los espacios legales previstos en la Ley de Participación Ciudadana, la Ley de Municipios y la Ley de Régimen Presupuestario Municipal. De acuerdo a Ortega (2008, p.14), "en este marco se diluyen los niveles de gobierno y la autonomía de los gobiernos locales, concentrándose las decisiones en el presidente".

Según una encuesta realizada en 2009, en los CPC participa entre el 5-7\% de los nicaragüenses, de los cuales, el 81.0\% se identifica con el FSLN (Stuart, 2009, citado por Serra, 2010). Se trata de una forma de participación clientelista en la que los miembros obtienen beneficios del gobierno central a través de programas sociales y económicos. Los GPC han afectado el quehacer de los Comités de Desarrollo Municipal vaciando su función al crear una instancia paralela o controlando el espacio legal (Red Local, 2008, citado por Serra, 2010). Pese a la promoción de estas organizaciones, las comunidades indígenas y afro descendientes del Caribe han optado por mantener sus propias organizaciones tradicionales.

Por otra parte, el gobierno actual ha promovido una campaña de desprestigio y control de las organizaciones y medios de comunicación no afines al FSLN. A 
esto se suman los impedimentos que han tenido para fiscalizar el desempeño de los funcionarios públicos, el gasto público y el acceso a la información ciudadana.

En síntesis, la sociedad civil se encuentra fragmentada en tres grupos: las OSC aliadas al FSLN, las OSC autónomas del gobierno - que demandan participar en incidencia y auditoría de políticas públicas - y las OSC que actúan según los intereses de sus miembros sin mayor vinculación con el Estado y sin adoptar una posición frente al gobierno.

\subsection{Composición de la sociedad civil en Nicaragua y el marco institucional}

Serra (2010) agrupa las OSC en sindicatos, cooperativas, organizaciones comunales, grupos de interés, organizaciones de desarrollo y redes nacionales de OSC ${ }^{2}$. Existen 850 sindicatos, en los que están inscritos 180,000 obreros (4.5\% de la PEA); 6,600 cooperativas con más de 500,000 socios/as que trabajan en ahorro y crédito, transporte, agua potable, producción agropecuaria, pesca, minería, textil, artesanías, turismo y construcción de viviendas; organizaciones comunales en las áreas urbanas y rurales que son la mayoría de las OSC, que trabajan por el desarrollo local en actividades de salud, educación, agua potable, luz eléctrica, deportes, cultura y arte, medio ambiente, seguridad, transporte, construcción y mantenimiento de infraestructura. Además, se encuentran los grupos de interés, en los que están involucradas asociaciones de profesionales, discapacitados, jubilados, consumidores, gremios empresariales, clubes deportivos y sociales, grupos por la diversidad sexual, centros culturales, organizaciones indígenas y religiosas, fundaciones filantrópicas y de servicios sociales.

Las organizaciones de desarrollo llamadas organizaciones no gubernamentales (son la minoría, 600-700 activas) son fundaciones o asociaciones sin fines de lucro que promueven el desarrollo socio-económico y cultural, en particular los derechos humanos, la participación ciudadana, la incidencia política, la asesoría a otras OSC, los servicios de salud, educación y asistencia. Las Redes Nacionales de Organizaciones Civiles intercambian experiencias e información, e inciden en las políticas públicas. Aunque existen más de 10 redes de sociedad civil importantes, la Coordinadora Civil (CC) es la red nacional más amplia, con unas 600 OSC socias.

En términos jurídicos existe un marco legal que facilita la organización y participación en la gestión pública de las OSC. La Constitución Política reconoce, en el arto. 49, el derecho de asociación voluntaria de los ciudadanos conforme a sus intereses particulares. Además, la carta magna establece las libertades básicas de expresión, participación y organización ciudadana, las cuales son reguladas por leyes particulares como: Ley de Municipios (Ley 40-1988), Ley de Participación Ciudadana (Ley 475-2003), Ley General sobre Personas Jurídicas sin fines de lucro (Ley 147-1992), Ley de Cooperativas (Ley 499-2004), Código del Trabajo (Ley 185. 1996) y Estatuto de Autonomía de las Regiones de la Costa Atlántica de Nicaragua (Ley 28- 1987). 
Especial interés tiene la legalidad de que dispone la participación ciudadana en la gestión de políticas públicas en los distintos niveles del Estado, así como el establecimiento de un sistema de espacios de concertación público-privada. La Ley de municipios contempla la participación de la ciudadanía a nivel local en los cabildos municipales, el Concejo Municipal, los Comités de Desarrollo y la Iniciativa Ciudadana. De igual manera, la Ley de Participación Ciudadana promueve la participación en la toma de decisiones de políticas públicas y las siguientes modalidades de participación: iniciativa ciudadana, consulta ciudadana, instancias consultivas y asociaciones sociales de pobladores, gremiales, sectoriales, mujeres y jóvenes. La Ley de Régimen Presupuestario Municipal (Ley 376-2001) y la Ley de Transferencias Presupuestarias a los Municipios (Ley 446-2003) establecen la consulta ciudadana para la elaboración del presupuesto del gobierno municipal.

\section{El problema de la participación de la sociedad civil a nivel regional}

La sociedad civil es un actor principal en el escenario de la gobernanza internacional que cobra fuerza desde la última década del siglo pasado a causa de la dinamización de la democracia como forma de gobierno en Europa del Este y América Latina. En este contexto la ciudadanía sobrepasa el carácter jurídico y se convierte, desde el punto de vista político, en una categoría central de la concepción de democracia en tanto sujeto con derechos políticos, civiles y sociales.

La reactivación del debate sobre la sociedad civil a partir de 1990 es una expresión más del proceso democratizador que se da en la región centroamericana. A diferencia de lo ocurrido en la democratización de las estructuras del Estadonación, el marco jurídico-político de la integración fue capaz de abrir un espacio institucionalizado (el CCSICA) para la participación de estos grupos. La razón: sin duda, el incentivo que la ampliación de los mercados generaba a los intereses económicos y comerciales de los sectores empresariales, que fueron quienes intentaron ocupar dicho espacio, sin conseguirlo. Más tarde, los diferentes tratados de integración incorporaron la constitución de otros espacios de consulta de la sociedad civil que estarían adscritos a las secretarías del SICA correspondientes.

En este artículo se define la sociedad civil como un espacio social que comprende las asociaciones $\mathrm{u}$ organizaciones y los movimientos sociales que, actuando a distintos niveles geográficos (local, nacional y regional), son ajenos al Estado, representan intereses diversos y trascienden el universo privado en el que surgen.

Como afirma Ortega (2008), el espacio de la sociedad civil es de carácter público, va más allá de la esfera familiar y se convierte en un espacio comunitario, pero es distinto al espacio estatal en el sentido que este último está determinado por la dinámica de la coerción y de la acción de sus aparatos para ejercer su autoridad y regular el ejercicio del poder.

La sociedad civil se caracteriza por ser heterogénea, autónoma del Estado, auto representada, auto organizada y voluntaria. En otras palabras, "la cultura política asociacionista, permite superar las formas tradicionales de clientelismo, populismo 
y corporativismo presentes en la historia política de América Latina y afianzar por tanto, la ciudadanía como base fundamental de la nueva relación de los ciudadanos con el Estado" (Ortega, 2008, p.12).

Existen dos enfoques teóricos para el estudio de la sociedad civil: el enfoque liberal y la perspectiva tripartita. El primer enfoque - cuyo máximo exponente es Hegel - se enfoca en el enfrentamiento Estado-sociedad civil, propio de la democracia liberal, como esferas que pugnan por la primacía y el control de la sociedad. El segundo enfoque, compartido por Cohen y Arato (2000), se refiere a la segmentación analítica de la esfera económica del ámbito de la sociedad civil, quedando configurada esta última como un espacio de interacción social con la economía y el Estado. La visión tripartita nos revela tres tipos de sociedad: sociedad política, sociedad económica y sociedad civil.

Los enfoques teóricos antes esbozados sostienen que la sociedad civil tiene como interlocutor y punto de referencia al gobierno en el marco de la teoría política del Estado-nación. Si es así, cabe la pregunta ¿quién es el actor con el que dialoga la sociedad civil dentro del proceso de integración regional? No hay que olvidar que la integración centroamericana es eminentemente intergubernamental, pues aún no se ha resuelto la creación de un órgano de gobierno sistémico que ejerza la gestión del sistema de forma autónoma (Santos Carrillo, 2010). La Reunión de Presidentes es el órgano que toma las decisiones sobre políticas regionales y la sociedad civil regional (incluyendo las institucionalizadas en comités y foros dentro del SICA) sólo participa en la consulta (cuestión que sigue sin ser de obligado cumplimiento por parte del SICA) que hagan los diversos órganos del sistema y otras instancias regionales e internacionales (organismos de cooperación, multilaterales u otros). En concreto, la sociedad civil no tiene, a nivel regional, un interlocutor claro que atienda sus demandas debido a que el proyecto integracionista está presidido por los gobiernos, aunque se reconoce que los espacios consultivos regionales se relacionan con las secretarías a las que están adscritos, secretarias que tienen una función administrativa y burocrática.

Tal como indica Santos Carrillo (2010), se carece de un órgano supranacional eficiente que rija el control de la integración centroamericana. Domina el intergubernamentalismo y la supeditación de la agenda regional a las distintas agendas nacionales. Existe desconfianza de buena parte de los actores de la sociedad civil, que no ven mayor rentabilidad al integrar los espacios consultivos formales debido a que el proceso consultivo no es de obligado cumplimiento y cuando lo hay, no tienen relación directa con los responsables políticos regionales. Por esta razón la sociedad civil regional decide, a través de sus representantes a escala nacional, entablar diálogo con los gobiernos nacionales, los decisores de la integración regional.

En el caso de los capítulos nacionales, según lo normado, el interlocutor es su homólogo en el ámbito regional, el CCSICA. No obstante, las evidencias empíricas de la dinámica del Capítulo Nicaragua revelan que el diálogo trasciende al CCSICA, pues se han acercado a las instituciones estatales para el abordaje de la temática referida al Acuerdo de Asociación y cambio climático, tal como se verá más adelante.

Las funciones de la sociedad civil en los procesos de integración regional han sido estudiadas por Santos Carrillo (2010). Por un lado está la lucha de 
organizaciones civiles en defensa de sus intereses y la consecución de mayores cuotas de participación en la toma de decisiones, a propósito de la democracia. Por otro lado, el problema de la representatividad reduce la capacidad de actuación y la confianza por parte de las instituciones. Todo esto ocurre en un escenario donde todavía hay muestras de clientelismo, populismo y corporativismo. Por consiguiente, tenemos una sociedad política que controla la mayoría de los procesos y que desconfía de la labor complementaria y legitimadora (no sustitutiva) que ofrece la colaboración civil y carece de voluntad para implementar estrategias participativas.

Aunque haya cierto interés y a la vez desconfianza por la inclusión de la sociedad civil en el proyecto integracionista, no hay que olvidar que el sistema legal ha institucionalizado la participación de la sociedad civil. Entonces, habría que preguntarse por el tipo de relación que establecen los espacios institucionalizados de la sociedad civil con cualquiera de los órganos del SICA que demandan la consulta. En este sentido, la práctica y la normativa (Comité Consultivo del Sistema de Integración Centroamericana [CCSICA], 2007) muestran que son relaciones predominantemente de consulta, propuesta e incidencia sobre la política de la organización regional y el proceso de integración centroamericana con el alcance que precisa el Protocolo de Tegucigalpa (Sistema de Integración Centroamericana, 1991). A esto habría que agregar las relaciones de tensión y oposición que establecen las organizaciones que se mantienen al margen de dichos espacios institucionalizados (denominados organizaciones outsider).

La preeminencia del carácter consultivo de la sociedad civil en el proceso integracionista ha sido objeto de crítica por parte de algunas organizaciones civiles que participan en dichos espacios y de aquellas que han sabido aprovechar otras plataformas para realizar incidencia. Muchas de estas organizaciones de la sociedad civil demandan la participación en la toma de decisiones, tal y como sucede en las políticas públicas en los ámbitos territoriales y nacionales de los países que la componen.

La sociedad civil centroamericana en el proceso de integración regional aparece, como ya dijimos, en calidad de actor emergente en los años 90 en un contexto donde están por un lado las políticas neoliberales condicionadas por el Fondo Monetario Internacional y el Banco Mundial junto con el debilitamiento del Estado y, por otro lado, el establecimiento de regímenes democráticos representativos y el apoyo técnico y económico. Adicionalmente, se presenta el reconocimiento, por parte de organismos internacionales, de la sociedad civil como agente principal del desarrollo y la democracia, más la reactivación del proceso integracionista.

El interés de la integración surge inicialmente de una parte de la sociedad civil, precisamente aquella cuya naturaleza se cuestiona como parte de la sociedad civil: los sectores empresariales de la región. Como resultado, aparecen plataformas de organizaciones de la sociedad civil que alertan sobre tal situación e inician un proceso de incidencia hasta conseguir bloquear este primer intento por cooptar este espacio que se abre en el seno del SICA.

Los foros denominados Comité Centroamericano de Coordinación Intersectorial (1992) e Iniciativa Civil para la Integración Centroamericana (1994), se constituyen en el antecedente del CCSICA, espacio consultivo de carácter general conformado en 1995. El funcionamiento de este espacio consultivo fue poco 
sistemático y organizado desde sus orígenes, cuestión que puede cambiar debido a que desde el año 2006 dispone del Plan de Acción para su fortalecimiento, gracias al apoyo financiero de la Unión Europea en el marco del Plan Apoyo a la Integración Regional (PAIRCA). El Plan de Acción para el fortalecimiento consultivo tiene tres ejes fundamentales: fortalecimiento gerencial, fortalecimiento orgánico y operativo, y fortalecimiento estratégico.

Las organizaciones civiles regionales que participan en el proyecto integracionista se caracterizan por:

- Ser heterogéneas: provienen de distintas nacionalidades, sectores y grupos, e incluyen asociaciones civiles que pertenecen al ámbito económico y social.

- Tener un origen común: surgen en respuesta a las políticas neoliberales que empiezan en los años 80.

- $\quad$ Ser autónomas del Estado (por ejemplo, el CCSICA ha establecido criterios propios de autonomía y representatividad)

- Apostar por un modelo de participación de doble vía: de abajo hacia arriba y a la inversa, como una manera de articular los espacios locales, nacionales y supranacionales.

- Tener una limitada estructura organizativa pero saber utilizar las tecnologías de la información para comunicarse intragrupo y exponer posicionamientos o propuestas alrededor de procesos claves (Santos Carrillo, 2010).

La capacidad de incidencia y propuesta de la sociedad civil regional en el proyecto integrador ha sido limitada por varias razones. Por un lado, tienen una débil estructura organizativa, capacidad limitada de incidencia y participación en la esfera pública, carencia de capacitación técnica, falta de recursos económicos y apoyo institucional, y división de la participación en espacios formales e informales. Por otro lado, hay un escaso interés por parte de los gobiernos para considerar los planteamientos de la sociedad civil, actor al que se reprocha no ser representativo y al que se ve como un receptor de políticas públicas. Además, en el proyecto integracionista encontramos que se otorga al CCSICA el rol de asesor de la SGSICA, instancia que no toma decisiones, sino que tiene una función administrativa. A esto se suma el desconocimiento del proyecto integracionista por parte de las ciudadanías nacionales (Santos Carrillo, 2010).

\section{Marco jurídico-institucional que establece el funcionamiento del CCSICA y los capítulos nacionales}

El Protocolo de Tegucigalpa, aprobado en 1991, crea el Comité Consultivo del Sistema de Integración Centroamericana (CCSICA) adscrito a la Secretaría General del SICA (SGSICA). El comité consultivo tiene carácter general y está compuesto por 27 organizaciones que proceden de diversos ámbitos (laboral, académico, grupos de población, empresarial, de indígenas, de afrodescendientes, etc.).

El espacio ha tenido poca transcendencia en el proceso de integración centroamericana dado que la facultad consultiva no es obligatoria. Otra dificultad es la ausencia de vínculos de jerarquización con el resto de los comités consultivos 
del SICA: Comité Consultivo de Integración Económica, el Foro de la Sociedad Civil de Ambiente y Desarrollo y el Comité Consultivo de Integración Social, lo que genera disfuncionalidad y tensiones entre los actores. La independencia en la que se forja esta sociedad civil, la falta de financiación por parte de las instituciones del SICA, la heterogeneidad de intereses y el carácter federal de muchas organizaciones, terminan dando lugar a actuaciones unilaterales y conductas erráticas, ofreciendo una imagen de desorganización e improvisación en torno a las actuaciones de estas organizaciones (Santos Carrillo, 2009).

A partir de 2005 el CCSICA dispone de capítulos nacionales, espacios que surgen de la necesidad de vincular al comité con las organizaciones del ámbito nacional o local que por sus propias condiciones no podían formar parte del mismo. El Reglamento General para los capítulos nacionales (Comité Consultivo del Sistema de Integración Centroamericana [CCSICA], 2010a, p.1) define a estos espacios como "instancia de apoyo y colaboración del Comité Consultivo, para contribuir en el ámbito nacional en el desarrollo de los espacios de reflexión, análisis y promoción de la integración centroamericana, con el fin de asegurar la participación e incidencia de los amplios sectores de la sociedad." Los capítulos nacionales estarían conformados por las organizaciones nacionales miembros del CCSICA en el ámbito regional y otras organizaciones nacionales y regionales residentes en el país que, por su experiencia, conocimiento e interés en los temas del desarrollo y la integración centroamericana, puedan hacer propuestas calificadas dentro del marco del CCSICA. Este documento señala que la relación de los capítulos nacionales con la estructura del SICA se hace a través del Directorio del CCSICA.

En la versión modificada del estatuto constitutivo del CCSICA, acordada en la Asamblea Plenaria de Managua de 2007, se incorporan los capítulos nacionales como un órgano más de la estructura del CCSICA, según consta en el art. 18 del Capítulo V. De igual modo, sus características y funciones, se exponen en el art. 33 del Capítulo V:

- Los capítulos nacionales son instancias de apoyo y colaboración del CCSICA en el ámbito nacional.

- $\quad$ Funcionarán como enlace entre el Directorio y la Asamblea Plenaria del CCSICA con las organizaciones nacionales de la sociedad civil.

- Se desempeñan como vehículos y espacios para la reflexión, análisis y promoción de la integración centroamericana.

- Podrán desarrollar, desde la perspectiva nacional y en contribución a la agenda regional, estudios y análisis acerca de la integración; sus debilidades y potencialidades.

- Pueden elaborar y elevar al Directorio o a la Asamblea Plenaria del CCSICA, a través de éste o de alguna/s de las organizaciones regionales miembros del CCSICA, propuestas que fortalezcan su accionar y la integración centroamericana.

- Su agenda estará orientada a los asuntos regionales o de la integración regional, por lo que no deberán concebirse como entidades que puedan sustituir a las organizaciones nacionales de las sociedades civiles, pero sí contribuir a su fortalecimiento. 
En lo que se refiere a la estructura de los capítulos nacionales, están dotados de una Asamblea Plenaria en la que participan miembros plenos y colaboradores, un directorio (compuesto de un máximo de siete representantes) y un presidente del capítulo.

Aun cuando los capítulos nacionales están conformados en seis países de Centroamérica (con excepción de El Salvador), el seguimiento, la operatividad y la incidencia de los diferentes comités ha sido muy débil. En general, tienen escasa capacidad propositiva. Además, la interrelación entre el CCSICA y los capítulos nacionales ha sido coyuntural pese a que el Plan Estratégico del CCSICA de 2006 tiene como uno de sus ejes estratégicos el fortalecimiento de estos espacios nacionales (Santos Carrillo, 2010).

\section{Dinámica del Capítulo Nicaragua y su articulación con el CCSICA y el resto de capítulos nacionales}

\subsection{Perfil del Capítulo Nicaragua}

El Capítulo Nicaragua se constituyó el 13 de octubre de 2005. Está compuesto por 40 miembros plenos distribuidos de la siguiente manera:

- Tres organizaciones nacionales asociadas a redes regionales miembros del CCSICA: Coordinadora Centroamericana de Trabajadores (COCENTRA), Foro de Mujeres para la Integración Centroamericana (FMICA) y Consejo Indígena Centroamericano

- 37 organizaciones nacionales y/o regionales con residencia en el país, que están interesadas en la promoción y defensa del proceso de integración centroamericana. La mayoría de las organizaciones son de mujeres (15 en total) vinculadas a derechos indígenas, derechos políticos y al ámbito productivo. Le sigue el sector académico, con la presencia de universidades públicas y privadas y el Foro Nacional de Educación; el sector sindical más las cooperativas y organizaciones de productores. En menor medida encontramos organizaciones que trabajan el tema de los derechos humanos, étnicidad, niñez, diversidad sexual, medio ambiente y seguridad ciudadana.

También dispone de dos miembros colaboradores: Federación Nacional de Cooperativas (FENACOOP) y el Instituto Centroamericano para la Integración (ICI), de la Universidad American College. Se trata de miembros que participan como ponentes en foros y seminarios, que asesoran y brindan asistencia técnica al Capítulo.

En términos organizativos el espacio dispone de una asamblea plenaria y un Comité de Coordinación interino. La Asamblea es la máxima autoridad, tiene la potestad de participar en los estudios, análisis, propuestas y acuerdos del Capítulo, en la admisión de miembros y en la elección de la junta directiva. El Comité de Coordinación provisional asegura el vínculo entre los ámbitos regional y nacional, convoca a reuniones por iniciativa propia o a solicitud de la Asamblea Plenaria, formula y da seguimiento a estudios y propuestas relacionados con la integración 
centroamericana, coordina los debates de la Asamblea del Capítulo Nacional y elabora las correspondientes actas e informes, define su propia organización interna para su funcionamiento, y establece los procedimientos de aceptación de miembros plenos y colaboradores (CCSICA, 2010a).

El Comité de Coordinación está compuesto por seis miembros electos interinamente: tres provienen de organizaciones nacionales con representación regional en la Asamblea Regional del CCSICA, mientras que otros otres representan organizaciones civiles nacionales. Sus miembros actuales pueden observarse en el Cuadro 1. Además, para el año 2011 la Asamblea General llevaría a cabo el proceso de elección del Comité de Coordinación.

Cuadro 1. Miembros del Comité de Coordinación Provisional según la organización que representan y tipo de organización

\begin{tabular}{|l|l|l|}
\hline Nombres y apellidos & $\begin{array}{l}\text { Organización que } \\
\text { representa }\end{array}$ & $\begin{array}{l}\text { Tipo de organización/ } \\
\text { organización a la que } \\
\text { pertenece a nivel regional }\end{array}$ \\
\hline $\begin{array}{l}\text { Haydee Castillo Flores } \\
\text { Coordinación }\end{array}$ & $\begin{array}{l}\text { Foro de Mujeres } \\
\text { para la Integración } \\
\text { Centroamericana } \\
\text { (FMICA) }\end{array}$ & Regional/FMICA \\
\hline $\begin{array}{l}\text { Miguel Ruíz } \\
\text { Vice-coordinación }\end{array}$ & $\begin{array}{l}\text { Central Sandinista de } \\
\text { Trabajadores (CST) }\end{array}$ & $\begin{array}{l}\text { Regional/Coordinadora } \\
\text { Centroamericana } \\
\text { de Trabajadores } \\
\text { (COCENTRA) }\end{array}$ \\
\hline Mario Gutiérrez & $\begin{array}{l}\text { Red de Diversidad Sexual } \\
\text { (RDS) }\end{array}$ & Nacional \\
\hline Ximena Ramírez & $\begin{array}{l}\text { Congreso Permanente de } \\
\text { Mujeres Empresarias de } \\
\text { Nicaragua (CPMEN) }\end{array}$ & Nacional \\
\hline Aminadad Rodríguez & $\begin{array}{l}\text { Movimiento Indigena } \\
\text { Nicaragüense (MIN) }\end{array}$ & $\begin{array}{l}\text { Regional/Consejo Indigena } \\
\text { Centroamericano }\end{array}$ \\
\hline Mirna Taylor & $\begin{array}{l}\text { Asociación de Mujeres } \\
\text { Indígenas de la Costa } \\
\text { Atlántica (AMICA) }\end{array}$ & Nacional \\
\hline
\end{tabular}

Desde la conformación del capítulo nacional ha prevalecido el liderazgo de los/as representantes del FMICA, la Central Sandinista de Trabajadores José Benito Escobar (CST- JBE), el Congreso Permanente de Mujeres Empresarias (CPMEN), la Asociación de Mujeres de la Costa Atlántica (AMICA) y el Movimiento Indígena Nicaragüense (MIN).

Según la opinión de los entrevistados y entrevistadas, falta la presencia del Movimiento de Productores, del Consejo Superior de la Empresa Privada (COSEP), de representantes de la pluralidad de la micro, pequeña y mediana empresa, de las 
diferentes centrales del sector sindical, de organizaciones civiles locales de todas las regiones de Nicaragua, del sector agroforestal y de la juventud. También es necesario un mayor protagonismo del sector académico, del campesino y del Movimiento Cooperativo de Nicaragua.

Hace falta profundizar en la representatividad de las organizaciones que forman parte del Capítulo. No obstante, algunos ejemplos ya ponen en entredicho este indicador para algunos sectores. El sector sindical en Nicaragua estaba conformado en el año 2006 por 178, 013 trabajadores aglutinados en tres confederaciones y tres sindicatos independientes (FNT, 2006, citado por Serra, 2007). La Central Sandinista de Trabajadores José Benito Escobar (CST-JBE) y la Confederación de Unidad Sindical, que forman parte del Capítulo Nicaragua, apenas representan el 20.0\% (35,000 trabajadores). Algo similar ocurre con las organizaciones de pueblos y comunidades indígenas, que ascendían a un total de 47 organizaciones (MITRAB, 2006, citado por Serra, 2007). En el Capítulo Nicaragua hay tres organizaciones de este tipo: Asociación de Mujeres Indígenas de la Costa Atlántica (AMICA), Movimiento Indígena Nicaragüense (MIN) y Organización Negra Centroamericana (ONECA).

El Capítulo Nicaragua ha elaborado un Plan Estratégico 2010-2015 (Comité Consultivo del Sistema de la Integración Centroamericana. Capítulo Nicaragua [CCSICA Capítulo Nicaragua], 2010), cuyos objetivos son : a) consolidar al CCSICA como un espacio de articulación y de gestión de las políticas públicas económicas, socioculturales, ambientales y de seguridad en el marco de la diversidad cultural, de los pueblos indígenas y afro descendientes, de género, sexuales y generacionales en Nicaragua; b) desarrollar capacidades de análisis, investigación, propuesta e incidencia del CCSICA Nicaragua, en el proceso de integración, que contribuyan a una cultura democrática y de respeto a los derechos humanos en Centroamérica (CCSICA Capítulo Nicaragua, 2010). Es notable que las prioridades del capítulo nacional son amplias en el sentido que apuestan por el fortalecimiento institucional del espacio de concertación, de tal manera que la incidencia frente a las distintas políticas regionales se realice en consenso y con la calidad técnica requerida. La gestión de recursos económicos para la puesta en marcha del plan aparece como una prioridad pues el CCSICA no dispone de una partida presupuestaria. Existe un debate importante acerca de quién debe financiar la participación.

\subsection{Acciones del Capítulo Nicaragua}

La labor del Capítulo Nicaragua está orientada a la incidencia en la agenda de la integración centroamericana. Dicho órgano concibe la incidencia política como un proceso a mediano y largo plazo para propiciar cambios en las políticas públicas regionales. Tres han sido las formas de incidencia: análisis de las problemáticas, formulación de propuestas de consenso y pronunciamientos relacionados con la integración regional. Las demandas o propuestas son compartidas con actores estatales, funcionarios del SICA, miembros del CCSICA y de la cooperación.

Las consultas llevadas a cabo por el Capítulo durante el período 2005-2011 proceden en su mayoría de iniciativas propias y no de convocatorias hechas por la Asamblea Plenaria o el Directorio del CCSICA. Por iniciativa propia ha elaborado 
pronunciamientos sobre trata de personas, migración, empleo, violencia hacia las mujeres, cambio climático, pueblos indígenas, conflicto limítrofe entre Costa Rica y Nicaragua, y Estrategia de Seguridad en Centroamérica. También participó en la Consulta que hiciera el CCSICA e instituciones estatales sobre el Acuerdo de Asociación entre Centroamérica y la Unión Europea (AdA) y asistió a la consulta del CCSICA sobre Cambio Climático.

Las respuestas a solicitudes de participación derivadas de instituciones estatales sobre el AdA distorsiona la competencia para la que fue creada el capítulo nacional, corriendo el riesgo de que este tipo de conducta se repita. La versión modificada del estatuto constitutivo del CCSICA de 2007, artículo 33 del Capítulo V, expone que "su agenda estará orientada a los asuntos regionales o de la integración regional, por lo que no deberán concebirse como entidades que puedan sustituir las organizaciones nacionales de las sociedades civiles, pero sí contribuir a su fortalecimiento" (p.22).

De las propuestas y pronunciamientos, tres han sido de gran relevancia. Han servido de base para el posicionamiento y la propuesta que hiciera el CCSICA ante las instancias correspondientes. Se trata de la propuesta elaborada por el Capítulo Nicaragua respecto al Acuerdo de Asociación entre Centroamérica-UE (AdA), cambio climático y la Estrategia de Seguridad de Centroamérica.

El Capítulo ha priorizado la agenda social del SICA al tratarse de una dimensión que ha sido incluida tardíamente en el Sistema. Además, el espacio tiene interés en seguir abordando los tópicos: reforma del SICA, cambio climático, efectos de los tratados comerciales (CAFTA y AdA), empleo pleno y digno de los/ as centroamericanos/as y migrantes dentro de la región. También hay dos temas nuevos sobre los que estarán trabajando a mediano plazo: inclusión del tema de la integración centroamericana en todos los niveles educativos e inserción de la perspectiva de género en el concepto político de la integración centroamericana.

\subsection{Valoración de la experiencia}

Entre los elementos facilitadores internos del Capítulo tenemos: el interés y compromiso de las organizaciones miembros; algunas organizaciones (FMICA, CSTJBE y el MIN) aportan al capítulo recursos materiales y ponen a disposición sus oficinas; reúne a organizaciones que conforman redes regionales, lo que permite intercambiar información y experiencias; muchas de las organizaciones que lo conforman tienen una base a nivel local; están abiertos a la integración de OSC, aun cuando éstas pertenecen a espacios que se definen como opuestos desde el punto de vista político-ideológico; existe respeto y apoyo entre los miembros plenos del Capítulo, que tienen identidad política e intereses sectoriales diferentes.

El capítulo nacional ha realizado una labor sistemática. Aun cuando algunas de las propuestas no han alcanzado el nivel de profundidad requerido, se ha divulgado el trabajo realizado a través de los medios de comunicación y de correo electrónico. Además, los miembros del capítulo han sido capacitados sobre temas relacionados con la integración regional y tienen comunicación estrecha con instituciones estatales (Ministerio de Industria, Fomento y Comercio, y en menor medida Cancillería de la República) y del SICA (Parlamento Centroamericano y la Corte Centroamericana de Justicia) presentes en Nicaragua. 
Respecto a los elementos facilitadores externos está la disposición de la creación de los Comités Sectoriales del $\mathrm{CCSICA}^{3}$, conformados por organizaciones especializadas que podrán emitir opiniones calificadas en temas sectoriales del proceso de integración centroamericana. Esto es importante por dos motivos. Por un lado, servirán para tratar simultáneamente diversos temas que son de interés de la Asamblea Plenaria del CCSICA. Por otro lado, son espacios que, junto a los capítulos nacionales, estarían fortaleciendo la capacidad consultiva del CCSICA. También está la disposición de fondos externos (sobre todo de la Fundación Friedrich Ebert Stiftung) para acciones de incidencia del Capítulo (no de funcionamiento interno).

Las dificultades internas manifestadas en las entrevistas son las siguientes: la reducida profundidad y nivel técnico de las propuestas, los pocos recursos técnicos y financieros, la carencia de equipamiento e infraestructura propia y de personal que trabaje a tiempo completo, se dispone de pocos miembros colaboradores que proporcionen una asistencia especializada. Es necesario más trabajo en equipo pues el quehacer del capítulo está concentrado en la coordinación del órgano y en dos organizaciones más. Ha habido discrepancias entre las organizaciones miembros para abordar los temas con perspectiva de género.

También existe poca participación de algunas organizaciones en las actividades del capítulo debido a diversas razones: escaso tiempo disponible de sus delegados/as, variados espacios en los que están las organizaciones, reducidos recursos económicos de que disponen las organizaciones y desinterés de las organizaciones civiles en algunos temas que se están abordando en el Capítulo. Según los/as entrevistados/ as, las organizaciones que menos asisten son: Centro Humboldt, Confederación de Unificación Sindical (CUS), Servicio de Información Mesoamericano sobre Agricultura Sostenible (SIMAS), Universidad Centroamericana (UCA), Comité de desarrollo Departamental (CDD) de Nandaime y Foro de Educación.

Con relación a las dificultades externas destaca que, a pesar del carácter multidimensional de la integración, siguen prevaleciendo los aspectos económicos y comerciales, descuidando los sociopolíticos y culturales. Hace falta un presupuesto comunitario y el cumplimiento de los mandatos presidenciales debido a que no existe articulación entre las políticas regionales y las nacionales (Caldentey del Pozo et al., 2010).

Muchas veces el CCSICA tiene una visión pasiva de su rol, espera ser consultado antes que hacer uso de su autonomía para proponer iniciativas ante las instancias correspondientes. En ocasiones, los órganos del SICA consultan tardíamente al CCSICA, lo que ha evitado al Capítulo Nicaragua poder elaborar propuestas, pero ni el CCSICA ni los comités nacionales cuentan con un reglamento de consulta.

El CCSICA ha enfatizado su accionar sobre el fortalecimiento institucional, descuidando el fortalecimiento, apoyo económico, técnico y político y el seguimiento de los capítulos nacionales. Las debilidades en el diseño institucional de los comités consultivos son un factor que influye en que la coordinación entre los capítulos 
y el CCSICA sea muy débil o incluso inexistente. El carácter consultivo del CCSICA desanima a organizaciones civiles que desean participar en la toma de decisiones del SICA. Asimismo, el CCSICA ha negado la membrecía a la Coalición Centroamericana de Gays, aun cuando cumplen con los requisitos establecidos en los estatutos del CCSICA, siendo una actitud discriminatoria que limita la calidad, la legitimidad y la representatividad de estos espacios.

A nivel nacional, "el gobierno de Nicaragua ha impulsado un régimen excluyente de organizaciones sociales, ha limitado los derechos de asociación y expresión de las organizaciones civiles no afines" (Serra, 2010, p. 59). Puede existir la cooptación por parte del gobierno o del sector empresarial de líderes de organizaciones civiles que participan en el Capítulo Nicaragua, teniendo como efecto la prevalencia de intereses gubernamentales o empresariales dentro del espacio. Además, según Serra (2007), el retiro de la cooperación bilateral, proveniente fundamentalmente de los países nórdicos, repercute en el funcionamiento de organizaciones de la sociedad civil nacional que no han logrado ser autosostenibles.

Otro aspecto destacado es que los países centroamericanos disponen de planes de desarrollo gubernamentales de corto plazo y no planes de desarrollo de nación de largo plazo. Esta misma dinámica se reproduce a nivel regional, impidiendo el desarrollo humano sostenible en la región y con ello, poder disponer de agendas de trabajo a largo plazo del CCSICA y los capítulos nacionales.

\subsection{Articulación del Capítulo Nicaragua con el CCSICA y el resto de capítulos nacionales}

La interrelación del Capítulo Nicaragua con el CCSICA ha tenido la ventaja de que la coordinadora del capítulo es miembro de la Asamblea plenaria del CCSICA. Sin embargo, los mecanismos de comunicación, retroalimentación y seguimiento del CCSICA al capítulo nacional son muy débiles. La vinculación del capítulo con el CCSICA ha sido para la presentación ante la Asamblea Plenaria del informe anual del capítulo y menos para consultas de algunos temas que son estratégicos para la región.

Los factores que limitan la vinculación entre el capítulo Nicaragua y el CCSICA son: pocos recursos económicos del CCSICA para cumplir con las funciones que le fueron asignadas; reducida consulta de la asamblea plenaria o del directorio del CCSICA a los capítulos nacionales, lo que ha provocado que el capítulo Nicaragua se auto convoque sin lograr que sus propuestas sean parte de una propuesta de carácter regional; y el CCSICA está en construcción, por lo tanto, su capacidad de incidencia política es limitada; falta de divulgación del quehacer de los capítulos nacionales en la página web del SICA. Además, la falta de inclusión formal de los coordinadores de los capítulos nacionales dentro del directorio del CCSICA dificulta la interlocución con este órgano regional, la disposición de información sobre la dinámica regional del CCSICA y la capacidad de dinamizar los capítulos.

La interlocución del Capítulo Nicaragua con otros capítulos nacionales es esporádica y circunstancial, lo que poco ayuda al fortalecimiento de la participación articulada de la sociedad civil de los países miembros. La vinculación ha tenido lugar en las asambleas plenarias del CCSICA, donde se exponen los informes anuales del 
quehacer de los capítulos y en las reuniones de las organizaciones regionales que conforman los capítulos nacionales.

\section{Conclusiones}

La participación de la sociedad civil en el proceso de integración centroamericana está aún en construcción. Recientemente, el CCSICA ha sido reconocido como órgano del Sistema, pero quedan por resolver la ambigüedad institucional y la poca solvencia económica con la que opera, entre otras limitantes.

El Capítulo Nicaragua está en proceso de constituirse en un espacio para la reflexión, el análisis y la promoción de la integración centroamericana. Como lo establece la versión modificada del estatuto constitutivo del CCSICA (2007), se ha activado para que desde las sociedades civiles de Nicaragua surjan temas regionales que debatir en el CCSICA, así como para responder a consultas dirigidas por el CCSICA. No obstante, ha sido convocado por instituciones estatales, ganando protagonismo en la configuración de agendas nacionales, cuestión que distorsiona la competencia para la que fue creado.

Han tenido poca comunicación y seguimiento de parte del CCSICA. Prácticamente no ha habido interlocución con el resto de los capítulos nacionales, cuestión que podría explicarse porque los estatutos constitutivos del CCSICA no lo regulan o conciben. Con esto, se está perdiendo la posibilidad de un mayor engranaje y comunicación entre capítulo nacional- resto de los capítulos nacionales-CCSICA.

El Capítulo Nicaragua ha sido beligerante en el posicionamiento político, pero débil en la formulación de propuestas técnicas. No obstante, se han preocupado por que los aspectos sociales de la integración centroamericana sean considerados, al igual que los aspectos económicos y políticos.

Entre los retos del capítulo nacional está la ampliación y fortalecimiento de su liderazgo como espacio de interlocución de organizaciones de sociedad civil interesadas en el proceso de integración. Se requiere establecer y regularizar los mecanismos de funcionamiento y comunicación entre sus miembros; desarrollar capacidades técnicas para la formulación de propuestas, incidencia y auditoría; y un mayor involucramiento de la ciudadanía local o territorial en los procesos de integración regional.

En definitiva, el Capítulo Nicaragua es una experiencia relevante para hacer notar el rol potencial que tienen las sociedades civiles nacionales para constituirse en espacios de análisis y propuestas para la integración centroamericana. Hace falta estudiar el resto de los capítulos nacionales para obtener una radiografía completa de este sistema de participación a nivel nacional. También se necesita indagar cómo funcionará el CCSICA con las mesas sectoriales y los capítulos nacionales. 


\section{Referencias bibliográficas}

Caldentey del Pozo, P., Romero, J. J., Santos Carrillo, F., Alonzo, E., Mata Amaya, E. R. \& Morticorena, K. (2010). SICA. Un breve vistazo al Sistema de la Integración Centroamericana. San Salvador: Fundación ETEA para el Desarrollo y la Cooperación.

Cohen, J. L. \& Arato, A. (2000). Sociedad Civil y Teoría Política. México: Fondo de Cultura Económica.

Comité Consultivo del Sistema de la Integración Centroamericana. Capítulo Nicaragua. (2010). Plan Estratégico Capítulo Nacional. CCSICA Nicaragua. Matriz de Planificación Operativa. Managua: Autor.

Comité Consultivo del Sistema de la Integración Centroamericana. (2010a). Reglamento General para los Capítulos Nacionales. San Salvador: Autor. CCSICA.

Comité Consultivo del Sistema de la Integración Centroamericana. (2010b). Reglamento General para los Comités Sectoriales. San José: Autor.

Comité Consultivo del Sistema de la Integración Centroamericana. (2007). Estatuto Constitutivo del Comité Consultivo del Sistema de la Integración Centroamericana CC-SICA. Managua: Autor.

Ortega, M. (2008). La relación gobierno-sociedad civil en el actual contexto. Managua: FONG-INGES.

Santos Carrillo, F. R. (2010). La Integración Regional Centroamericana y la Participación de la Sociedad Civil. Disertación Doctoral no publicada. Universidad de Córdoba. España.

Santos Carrillo, F. R. (2009). De la legitimación a la participación. El Comité Consultivo del Sistema de Integración Regional Centroamericano (CCSICA). Pensamiento Propio, (29), 55-89. Recuperado el 4 de abril de 2010, de http://www.cries.org/documentos_cries_old/29.pdf

Serra, L. (2007). La Sociedad Civil Nicaragüenses: sus organizaciones y sus relaciones con el Estado. Managua: CASC-UCA.

Serra, L. (2010). Índice de la Sociedad Civil Nicaragüense. Managua: Editronic,S.A. Sistema de Integración Centroamericana. (1991). Protocolo de Tegucigalpa a la Carta de Organización de Estados Centroamericanos (ODECA). Recuperado el 16 de abril de 2010, de http://www.sica.int/busqueda/busqueda_basica.aspx?idCat=\&i $\mathrm{dMod}=3 \& \mathrm{IdEnt}=1 \& \mathrm{Pag}=7$. 